\title{
Influences of silicon carbide nanowires addition on IMC growth behavior of pure Sn solder during solid-liquid diffusion
}

\section{Mulan Li}

Jiangsu Normal University

Liang Zhang ( $\square$ zhangliang@jsnu.edu.cn )

Jiangsu Normal University https://orcid.org/0000-0003-3757-7009

Jiang Nan

Jiangsu Normal University

Sujuan Zhong

Zhengzhou Research Institute of Mechanical Engineering

Lei Zhang

Zhengzhou Research Institute of Mechanical Engineering

\section{Research Article}

Keywords: SiC nanowires, Sn solder, IMC growth, solid-liquid diffusion

Posted Date: March 25th, 2021

DOI: https://doi.org/10.21203/rs.3.rs-351790/v1

License: (c) (i) This work is licensed under a Creative Commons Attribution 4.0 International License. Read Full License 


\title{
Influences of silicon carbide nanowires addition on IMC growth
}

\section{behavior of pure Sn solder during solid-liquid diffusion}

\author{
Mu-lan Li ${ }^{1}$, Liang Zhang ${ }^{1,2}$, Nan Jiang ${ }^{1}$, Su-juan Zhong ${ }^{2}$, Lei Zhang ${ }^{2}$ \\ 1 School of Mechatronic Engineering, Jiangsu Normal University, Xuzhou 221116, China; \\ 2 State Key Laboratory of Advanced Brazing Filler Metals \& Technology, Zhengzhou Research Institute of \\ Mechanical Engineering, Zhengzhou 450001, China.
}

\begin{abstract}
In this paper, various mass fraction (0, 0.2, 0.4, 0.6, 0.8, $1.0 \mathrm{wt} \%)$ of silicon carbide nanowires $(\mathrm{SiC})$ were incorporated into pure $\mathrm{Sn}$ solder to enhance the performances of $\mathrm{Sn}$ solder joint. The wetting behavior, shear strength and intermetallic compound (IMC) growth mechanism of $\mathrm{Sn}-x \mathrm{SiC} / \mathrm{Cu}$ solder during solid-liquid diffusion at $250{ }^{\circ} \mathrm{C}$ was investigated systematically. The experiment results demonstrated that the wettability of $\mathrm{Sn}-x \mathrm{SiC} / \mathrm{Cu}$ solder had a significant improvement when the addition of $\mathrm{SiC}$ was up to $0.6 \mathrm{wt} \%$, and excessive additives would degrade the wettability of the composite solder. The formation of the $\mathrm{Cu}_{6} \mathrm{Sn}_{5}$ IMC layer was observed at the $\mathrm{Sn}-x \mathrm{SiC}$ solder/Cu interface. Meanwhile, $\mathrm{SiC}$ as an additive was conducive to restraining the growth of interfacial IMC during soldering process and the IMC thickness overtly fell down after doping $0.8 \mathrm{wt} \%$ $\mathrm{SiC}$ into $\mathrm{Sn}$ solder. Moreover, $\mathrm{SiC}$ addition would contribute to enhancing the mechanical performance of Sn solder joint. The fracture mechanism of solder joint changed from a mix of brittle and ductile fracture to a characteristic of typical ductile fracture.
\end{abstract}

Keywords: SiC nanowires; Sn solder; IMC growth; solid-liquid diffusion

Correspondence: Liang Zhang, zhangliang@jsnu.edu.cn

\section{Introduction}

Sn-based solder, as a familiar material for the interconnection between substrates and parts of electron devices, provides for mechanical and electrical joints [1]. Solder joint is the product taken shape by the solder materials under the process of high temperature soldering, and its reliability is influenced by the formation of IMC at solder/substrate [2]. Due to the intrinsic brittleness of IMC, the joint strength will be degraded as the thickness of IMC layer increases remarkably, while thin IMC layer is conductive to improve the joint reliability with effect [3]. Numerous researches have been investigated the reaction at solder/substrate interface and the IMC growth kinetics of lead-free solder/substrate during soldering process [4]. Zhang et al.[5] pointed out that adding $0.5 \mathrm{wt} \%$ micro-sized CuZnAl particles into Sn58Bi put off the interfacial $\mathrm{Cu}_{6} \mathrm{Sn}_{5}$ and $\mathrm{Cu}_{3} \mathrm{Sn}$ IMCs growth and decreased voids formation. The same results were observed in the interfacial surface of $\mathrm{Cu} / \mathrm{Sn} 58 \mathrm{Bi} / \mathrm{Cu}[6]$. As for the interface of $\mathrm{Sn}-3.8 \mathrm{Ag}-0.7 \mathrm{Cu} / \mathrm{Fe}$ solder [7], CuZnAl particles could also hinder $\mathrm{FeSn}_{2}$ IMC growth and reduce its thickness. Jiang et al. [8] stated that choosing $0.1 \mathrm{wt} \%$ Ti nanoparticles as additives suppressed the growth of $\mathrm{Cu}_{6} \mathrm{Sn}_{5}$ IMC at interfacial $\mathrm{Sn} 58 \mathrm{Bi} / \mathrm{Cu}$ solder during reflowing.

Considering the inherent toxicity of lead element which is hazardous to the environment and individual health, many countries have legislated against the use of lead in electronic packaging $[9,10]$. So a range of lead-free Sn-based solders were selected as alternatives to $\mathrm{Pb}$-containing solder, such as binary or ternary $\mathrm{Sn}-\mathrm{Bi}, \mathrm{Sn}-\mathrm{Cu}, \mathrm{Sn}-\mathrm{Ag}-\mathrm{Cu}$ solder etc [11-13]. Additionally, researchers usually selected micro/nano-metric materials as strengthened additives added into pure $\mathrm{Sn}$ solder to promote the reliability of solder joints, such as single metallic particles or elements ( $\mathrm{Ag}, \mathrm{Bi}, \mathrm{Cu}$, etc.) [14-16] and carbon-based materials [17]. Sun et al. [18] demonstrated that $\mathrm{Cu}$ atoms in $\mathrm{Cu}$ substrate could react with $\mathrm{Sn}$ atoms in Sn solder rapidly at high temperature and two different IMC layers of the typical $\mathrm{Cu}_{6} \mathrm{Sn}_{5}$ and $\mathrm{Cu}_{3} \mathrm{Sn}$ were observed at the interface as the transient liquid phase bonding time increased. Meanwhile, 
micrometric $\mathrm{CuZnAl}$ particles added to $\mathrm{Sn}$ solder could absorb on the surface of Sn atoms, prohibiting the $\mathrm{Sn}$ and $\mathrm{Cu}$ atoms from reacting and then refraining interfacial surface IMC layer growth of $\mathrm{Cu} / \mathrm{Sn}-0.5 \mathrm{CuZnAl} / \mathrm{Cu}$. Also, there were studies $[17,19]$ that indicated that $0.075 \mathrm{wt} \%$ carbon nanotubes (CNTs) or $0.7 \mathrm{wt} \% \mathrm{Cu}$ nanoparticles as strengthening phases introduced into Sn solder decreased the interfacial $\mathrm{Cu}_{6} \mathrm{Sn}_{5}$ IMC thickness mostly. Moreover, $\mathrm{Ag}_{3} \mathrm{Sn}$ nanoparticles added to $\mathrm{Sn}$ solder could restrain the overgrowth of the interfacial $\mathrm{Cu}_{6} \mathrm{Sn}_{5} \mathrm{IMC}$ in that it would be aggregated on IMC surface and prevent $\mathrm{Sn}$ and $\mathrm{Cu}$ ions from diffusing at the solder/substrate interface [14].

In this paper, $\mathrm{SiC}$ was chose to be a strengthening phase due to its excellent mechanical properties. Various mass fraction ranging from $0 \mathrm{wt} \%$ to $1.0 \mathrm{wt} \%$ of $\mathrm{SiC}$ powders were incorporated into pure $\mathrm{Sn}$ solder to fabricate $\mathrm{Sn}-x \mathrm{SiC}$ composite solder. The growth behavior of $\mathrm{Sn}-\mathrm{Cu}$ IMC between $\mathrm{Sn}-x \mathrm{SiC}$ solder and $\mathrm{Cu}$ substrate after soldering at $250{ }^{\circ} \mathrm{C}$ was investigated. Additionally, the wettability and the shear resistance of $\mathrm{Sn}-x \mathrm{SiC}$ composite solder were also discussed.

\section{Experimental procedures}

\subsection{Materials preparation}

Halogen-free lead-free flux was blend with micro-sized Sn powder in a solder paste mixer at a ratio of 3:20 in order to fabricate pure Sn solder paste as matrix materials. As shown in Fig.1, the morphology of SiC was exhibited, and the diameter of $\mathrm{SiC}$ was $20-200 \mathrm{~nm}$ while the length of it was 2-30 $\mu \mathrm{m}$. The $\mathrm{Sn}-x \mathrm{SiC}(x=0,0.2,0.4,0.6,0.8,1.0 \mathrm{wt} \%)$ composite solder pastes, with the $\mathrm{SiC}$ powder and pure $\mathrm{Sn}$ solder paste as the raw materials, were synthesized via mechanical stirring. $\mathrm{Cu}$ sheets sized of $25 \mathrm{~mm} \times 25$ $\mathrm{mm} \times 0.20 \mathrm{~mm}$, as the substrates, were selected to be washed with alcohol in an ultrasonic clearing machine for $2 \mathrm{~min}$.

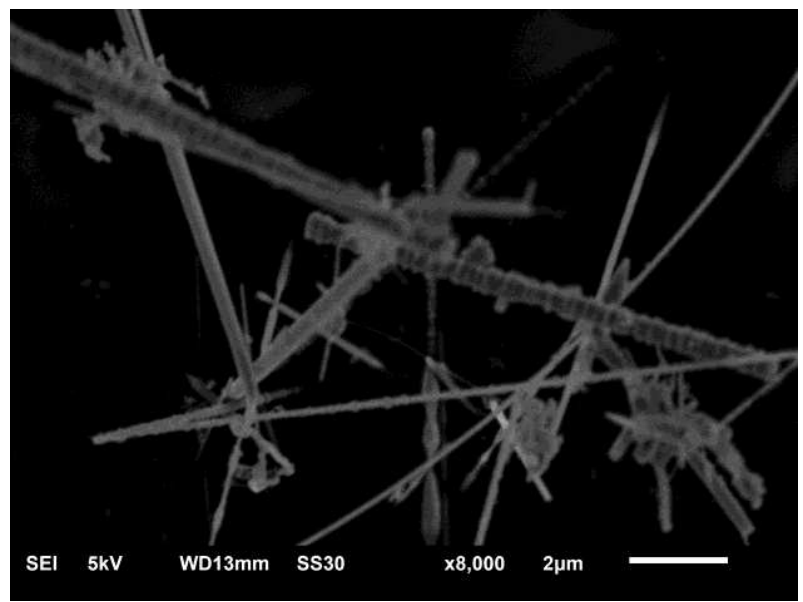

Fig.1 SEM image of SiC.

\subsection{Wettability}

As a rule, the wettability is characterized by the contact angle and spreading area [8]. In this experiment, wetting behavior was indicated by computing the spreading area. First of all, take $0.2 \pm$ $0.001 \mathrm{~g}$ of Sn- $x \mathrm{SiC}$ solder and place it on the center of $\mathrm{Cu}$ substrate respectively. Subsequently, the test specimens were heated by a graphite thermostatic heating plate at a peak temperature of $250{ }^{\circ} \mathrm{C}$ for $1 \mathrm{~min}$ and then move them away the heating plate when they were cooled to room temperature. Lastly, it is a necessity to take advantage of Image-J software to calculate the spreading areas three times, respectively, as to guarantee the accuracy of the test data.

\subsection{Interfacial IMC layer growth}

As for the kinetics of IMC layer growth at the interface of $\mathrm{Sn}-x \mathrm{SiC} / \mathrm{Cu}$, the $\mathrm{Sn}-\mathrm{SiC}$ samples were 
imbedded in resin epoxy after cutting that along the cross section. After that the inlaid specimens were grinded with abrasive paper and polished with diamond grinding paste. Afterwards, the cross section was corroded with a mixed solution of 5\% nitric acid and $95 \%$ alcohol for 4 seconds. Lastly, scanning electron microscope (SEM) was utilized to observe the interfacial IMC morphology. According to Eq.(1), the average thickness of interfacial IMC can be calculated:

$$
\chi=\frac{A}{L}
$$

where $\chi$ represents the mean thickness of IMC layer, $A$ represents the IMC layer area, $L$ represents the IMC layer length, as shown in Fig.2.

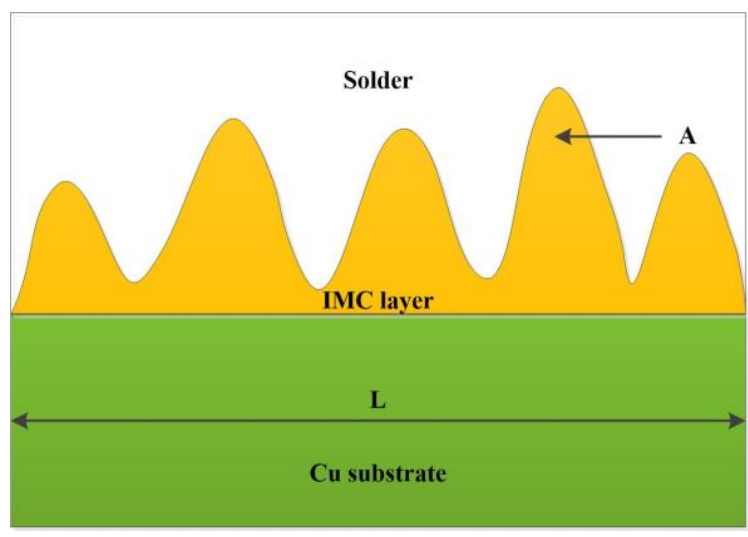

Fig.2 Diagrammatic drawing of interfacial IMC.

\subsection{Mechanical property}

For the shear experiment, the UTM5000 electronic universal testing machine, in a shear rate of $2 \mathrm{~mm} / \mathrm{min}$, was employed to acquire the shear strength value. The size of $\mathrm{Cu}$ sheets was $40 \mathrm{~mm} \times 4.0 \mathrm{~mm} \times 0.6 \mathrm{~mm}$ and the solder paste was about $0.50 \mathrm{~mm}$ in this test. The schematic diagram of shear test was obviously obtained in Fig.3. After the specimens conducted the soldering process, the shear test was made use of SEM to observe fracture morphology.

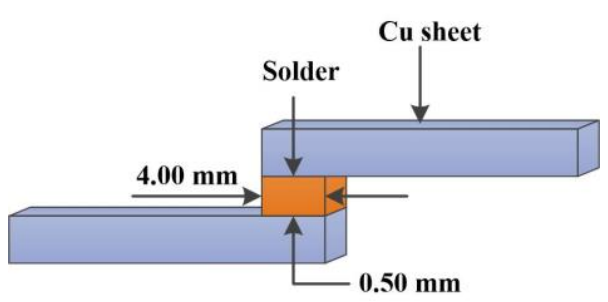

Fig.3 Diagrammatic drawing of shear test for $\mathrm{Sn}-x \mathrm{SiC}$ solder.

\section{Results and discussion}

\subsection{Wettability}

As shown in Fig.4, the spreading areas of $\mathrm{Sn}-x \mathrm{SiC}$ composite solder joints are obtained. What is vividly in the bar chart is that the wetting area firstly increases and then decreases with an increase of weight percentage of $\mathrm{SiC}$. When the amount of $\mathrm{SiC}$ added to pure $\mathrm{Sn}$ solder is up to $0.6 \mathrm{wt} \%$, the spreading area reaches $65.85 \mathrm{~mm}^{2}$, with an increase of $27.49 \%$ as compared to the pure Sn solder. Nevertheless, the spreading area has a precipitous decline as the addition of SiC is over $0.6 \mathrm{wt} \%$. The wettability improvement can be explained by the Young equation:

$$
\cos \theta=\frac{\xi_{\mathrm{gs}}-\xi_{\mathrm{ls}}}{\xi_{\mathrm{gl}}}
$$


where $\theta$ refers to the wetting angle, $\xi_{\mathrm{gl}}, \xi_{\mathrm{gs}}$ and $\xi_{\mathrm{ls}}$ refer to the interfacial tension of gas/fluid, gas/solid and fluid/solid, respectively. It is apparent that the smaller wetting angle means the larger spreading area, and the wettability of the solder performs better. Owing to the nanometric particles with high surface activity that tend to be absorbed on the solder surface, the surface tension of molten solder/substrate falls down and then the wettability of Sn solder containing SiC improves. Nevertheless, the excessive doping amount of $\mathrm{SiC}$ will appear agglomeration phenomenon in the solder matrix which contributes to a reduction of the viscosity of the $\mathrm{Sn}-\mathrm{SiC}$ composite solder and then the wettability of the molten composite solder deteriorates. Thus, so important appropriate content of SiC addition to $\mathrm{Sn}$ solder is that contributes to promoting the wettability of the solder.

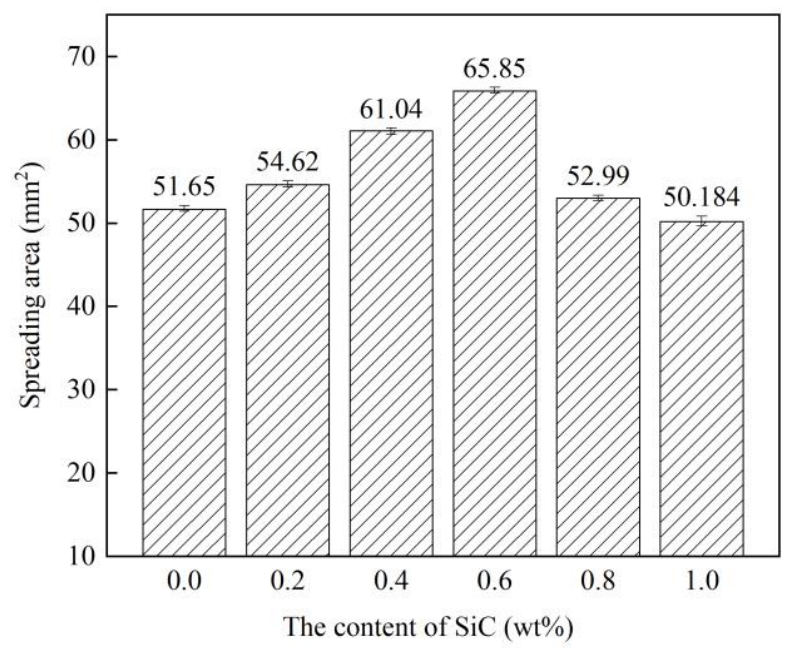

Fig.3 Column diagram of the spreading area varying with the addition content of SiC.

\subsection{Interfacial IMC layer growth}

Fig.4 exhibits the cross-sectional SEM image of $\mathrm{Sn}-x \mathrm{SiC} / \mathrm{Cu}$ interface after solid-liquid diffusion at $250{ }^{\circ} \mathrm{C}$ last for $1 \mathrm{~min}$ and the scallop-like IMC is formed at the interfacial $\mathrm{Sn}-x \mathrm{SiC} / \mathrm{Cu}$ solder joint after soldering. Through energy dispersive spectrometer (EDS) analysis as shown in Fig.5, it can be determined that the composition of IMC is $\mathrm{Cu}_{6} \mathrm{Sn}_{5}$ marked in Fig.4 (a). $\mathrm{Cu}_{6} \mathrm{Sn}_{5}$ IMC formation owes to the reaction of $\mathrm{Sn}$ element and $\mathrm{Cu}$ element diffusing from matrix and substrate, as described in Eq. (3):

$$
6 \mathrm{Cu}+5 \mathrm{Sn} \rightarrow \mathrm{Cu}_{6} \mathrm{Sn}_{5}
$$

It is obvious from Fig. 4 that the $\mathrm{SiC}$ addition performs some function in reducing IMC thickness. Fig.6 exhibits the mean IMC thickness of $\mathrm{Sn}-x \mathrm{SiC} / \mathrm{Cu}$ solder measured by Image-J software. From Fig.6, it demonstrates that the IMC layer thickness of $\mathrm{Sn}-x \mathrm{SiC} / \mathrm{Cu}$ solder joint is less than that of the $\mathrm{Sn} / \mathrm{Cu}$ solder joint, which reveals that adding SiC can suppress the IMC growth. Similar results were reported by Lee et al. [20] who stated that doping $\mathrm{SiC}$ could restrain the IMC growth at $\mathrm{Sn58Bi}$ solder/Cu interface with effect. As SiC addition increased, the IMC thickness at $\mathrm{Sn}-x \mathrm{SiC} / \mathrm{Cu}$ solder interface falls down. When the amount of $\mathrm{SiC}$ is up to $0.8 \mathrm{wt} \%$, the $\mathrm{Cu}_{6} \mathrm{Sn}_{5}$ layer thickness has a maximum reduction, in which case, the thickness of IMC layer is reduced to $7.18 \mu \mathrm{m}$ from $9.73 \mu \mathrm{m}$ in pure Sn solder, with a decrease of $26.21 \%$. On the one hand, the $\mathrm{Cu}_{6} \mathrm{Sn}_{5}$ layer gets thinner in that the $\mathrm{SiC}$ which nails at grain boundaries impedes the $\mathrm{Sn}$ and $\mathrm{Cu}$ atoms diffusion and then brings about the suppression of $\mathrm{Cu}_{6} \mathrm{Sn}_{5}$ growth. On the other hand, this can be attributed to the high surface energy of the nanoscale particles based on the adsorption theory, which can be described as following: 


$$
\sum_{\mathrm{K}} \gamma_{C}^{\mathrm{K}} \mathrm{A}_{\mathrm{K}}=\sum_{\mathrm{K}}\left(\gamma_{0}^{\mathrm{K}}-\mathrm{RT} \int_{0}^{C} \frac{\Gamma^{\mathrm{K}}}{C} \mathrm{~d} C\right) \mathrm{A}_{\mathrm{K}}
$$

where $C$ is the concentration of $\mathrm{SiC}, \mathrm{A}_{\mathrm{K}}$ is the surface area of $\mathrm{K}$ plane, $\gamma_{C}^{\mathrm{K}}$ is the unit surface tension of the $\mathrm{K}$ plane containing $\mathrm{SiC}, \gamma_{0}^{\mathrm{K}}$ is the unit surface tension of the $\mathrm{K}$ plane without $\mathrm{SiC}, \mathrm{T}$ is the absolute temperature, $\mathrm{R}$ is the Planck constant, $\Gamma^{\mathrm{K}}$ is the adsorption capacity of $\mathrm{SiC}$ at $\mathrm{K}$ plane. When the adsorption capacity of $\mathrm{SiC}$ reaches the maximum as the mass fraction of nanoparticles added up to $0.8 \mathrm{wt} \%$, the $\sum_{\mathrm{K}} \mathrm{A}_{\mathrm{K}} \int_{0}^{C} \frac{\Gamma^{\mathrm{K}}}{C} \mathrm{~d} C$ reaches a maximum, which means the total surface energy of $\mathrm{K}$ plane is minimal according to Eq.(4). In this case, it can be concluded that appropriate SiC addition can inhibit the growth of interfacial IMC. But further adding SiC into Sn solder, the interfacial IMC thickness gets larger than that of the $\mathrm{Sn}-0.8 \mathrm{SiC}$ solder. Excessive addition will weaken the inhibition effect on IMC growth. It may ascribe that the excess $\mathrm{SiC}$ dopants are prone to be agglomerates so as to decrease their adsorption capacity, which will result in the weaken of the IMC inhibition.
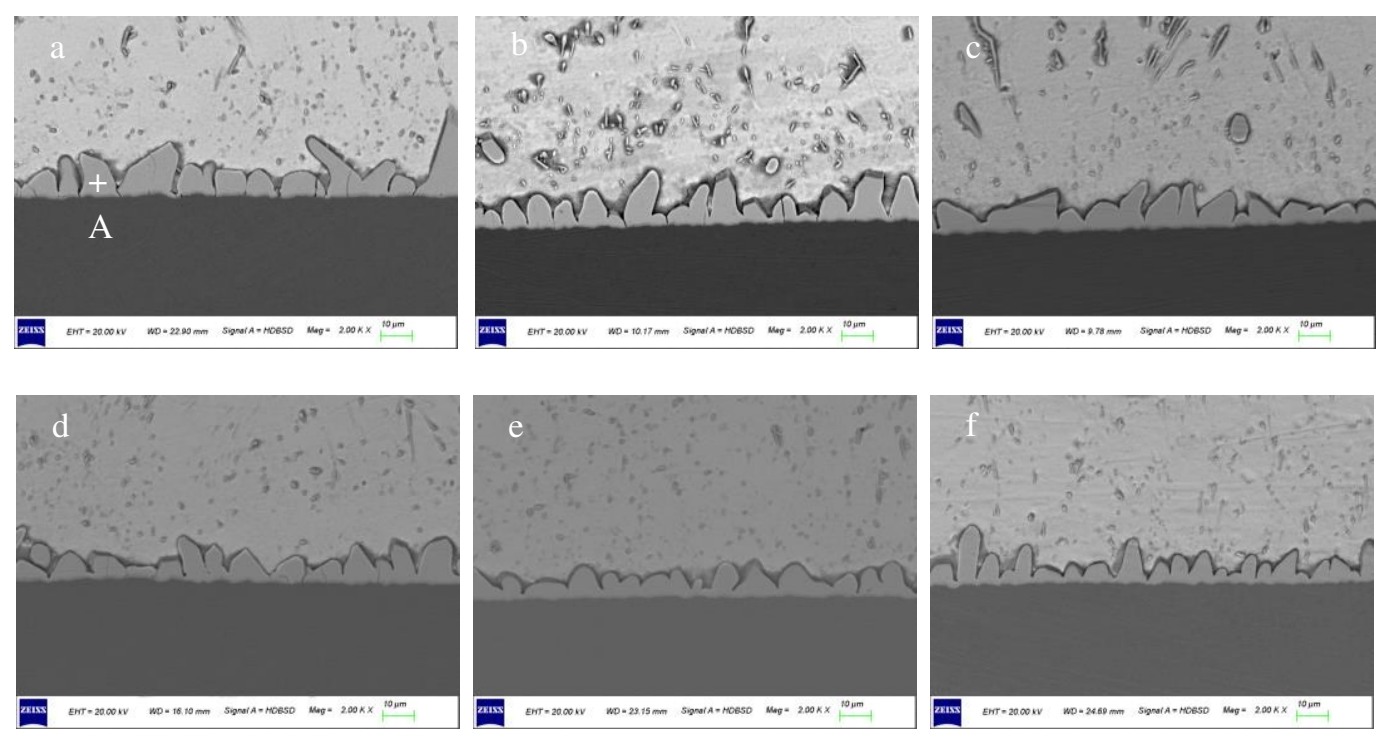

Fig.4 SEM morphology graph of the IMC at Sn- $x \mathrm{SiC} / \mathrm{Cu}$ solder heated at $250{ }^{\circ} \mathrm{C}$ for $1 \mathrm{~min}$ : (a) $x=0$, (b) $x=0.2$, (c) $x=0.4$, (d) $x=0.6$, (e) $x=0.8$, (f) $x=1.0$.

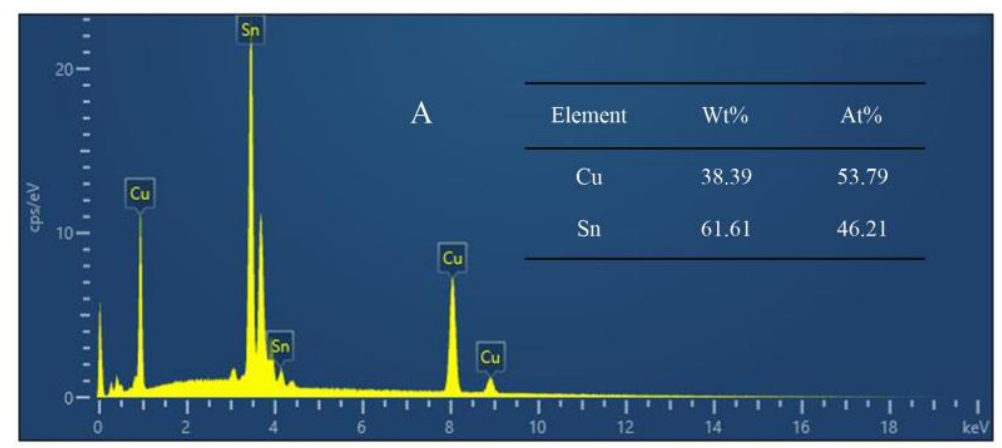

Fig.5 EDS analysis of IMC layer in Fig.4(a) 


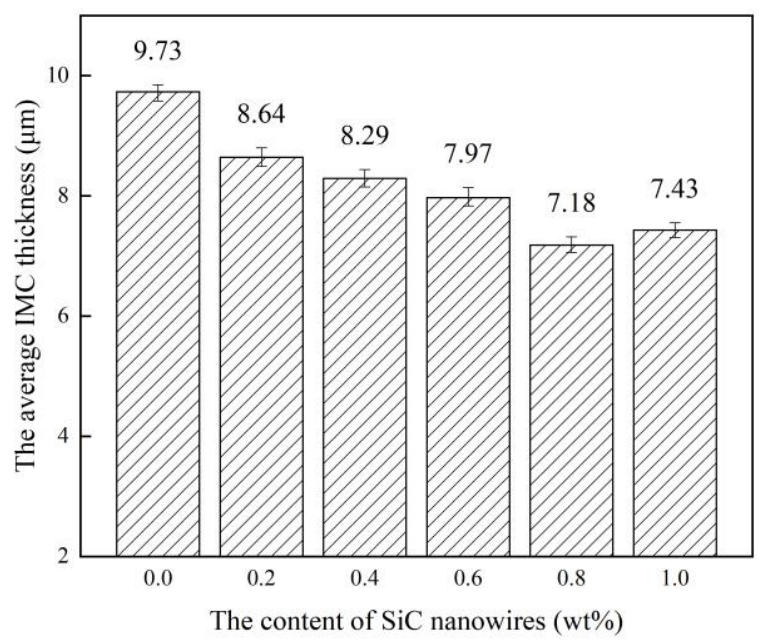

Fig.6 The average IMC thickness as different amount of SiC added to Sn solder.

\subsection{Mechanical property}

When it comes to the reliability of solder joint, the shear strength should be taken into account. As is shown in Fig.7, the shear strength varies with the mass fraction of $\mathrm{SiC}$ added into pure $\mathrm{Sn}$ solder. It can be conspicuously seen that doping $\mathrm{SiC}$ is conducive to strengthening the shear strength of pure $\mathrm{Sn}$ solder, an increase in the range of $0.977 \mathrm{MPa}-6.59 \mathrm{MPa}$. The shear strength puts on first and then falls down as the addition of $\mathrm{SiC}$ increased. When the amount of $\mathrm{SiC}$ added to $\mathrm{Sn}$ solder comes up to $0.8 \mathrm{wt} \%$, the shear strength of $\mathrm{Sn}-\mathrm{SiC}$ solder joint reaches a maximum value of $30.66 \mathrm{MPa}$ from $24.07 \mathrm{MPa}$ in pure $\mathrm{Sn}$ solder joint, an increase of $27.38 \%$. The enhancement in mechanical performances of $\mathrm{Sn}-x \mathrm{SiC}$ composite solder can be ascribed to dispersion strengthening and refinement strengthening mechanism. On one side, $\mathrm{SiC}$ dispersed in the solder matrix uniformly, tends to nail at IMC grain boundary and impede dislocation movement from generating. The dispersion strengthening can be clarified by the Orowan equation:

$$
\sigma=\frac{2 \mathrm{~Gb}}{\lambda}
$$

where $\sigma$ means the yield stress of the material, b means the Burger's vector of dislocation, $\mathrm{G}$ means shear modulus of the material and $\lambda$ means the average grains spacing in the solder matrix. Doping SiC decreases the mean spacing of the dispersed grains, contributing to the enhanced mechanical performances in accordance with Eq. (5). On the other side, SiC added into Sn solder can exist as nucleation sites and then refine the microstructure of composite solder, resulting in the strengthened shear strength owing to the Hall-Petch relationship that can be expounded as following:

$$
\sigma_{\mathrm{y}}=\sigma_{0}+\frac{\mathrm{K}}{\sqrt{d}}
$$

where $\sigma_{\mathrm{y}}$ equals to 0.2 times yield strength of material, $d$ is the mean size of grains, $\sigma_{0}$ and $\mathrm{K}$ are material constants. What's more, the IMC layer connected with solder and substrate is characterized by brittleness [6], and therefore thicker IMC layer will degrade the bonding strength of solder joints. Meantime, the $\mathrm{Sn}-0.8 \mathrm{SiC}$ solder exhibits the thinner IMC thickness in comparison to pure Sn solder that is linked with the better bonding strength, significantly enhancing the mechanical performances of the composite solder joints, and then its shear strength is improved. In this condition, it is obvious that the shear strength gradually decreases when the content of $\mathrm{SiC}$ is over $0.8 \mathrm{wt} \%$, which is concerned with the agglomeration phenomenon caused by adding powder too much brings about the increase of grain size and the 
thickening of IMC layer.

The fracture morphologies of shear tested specimens are revealed in Fig.8. As shown in Fig.8 (b)-(f), after adding $\mathrm{SiC}$ into $\mathrm{Sn}$ solder, there are more dimples appearing in SEM morphology in comparison to Fig.8 (a). Meanwhile, the fracture mode of solder joint turns a brittle and ductile mixed mode to a ductile one, which is a reason that the shear strength of composite solder joint is superior than pure Sn solder joint. Among them, Fig.8 (e) exhibits the most dimples distributed in fracture surface and therefore the $\mathrm{Sn}-0.8 \mathrm{SiC}$ composite shows the best performance in the shear strength. Nonetheless, when the addition of $\mathrm{SiC}$ is excessive, the number of ductile dimples is decreased, giving rise to a reduction of shear strength. From what has been discussed above, we may safely come to a conclusion that the appropriate amount of $\mathrm{SiC}$ addition is $0.8 \mathrm{wt} \%$ in strengthening the mechanical performances of $\mathrm{Sn}-\mathrm{SiC}$ composite solder greatly.

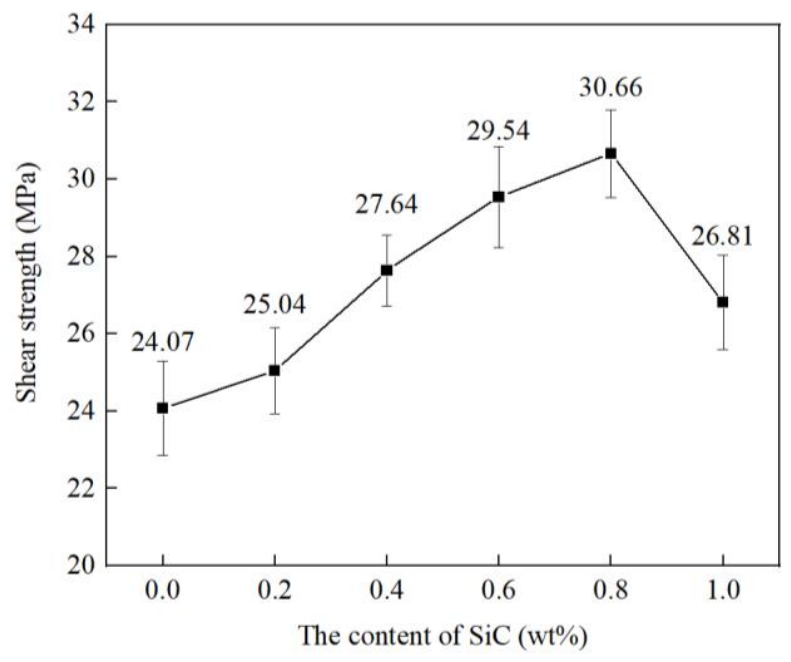

Fig.7 Curve graph of the shear strength as a function of SiC amount in Sn solder.
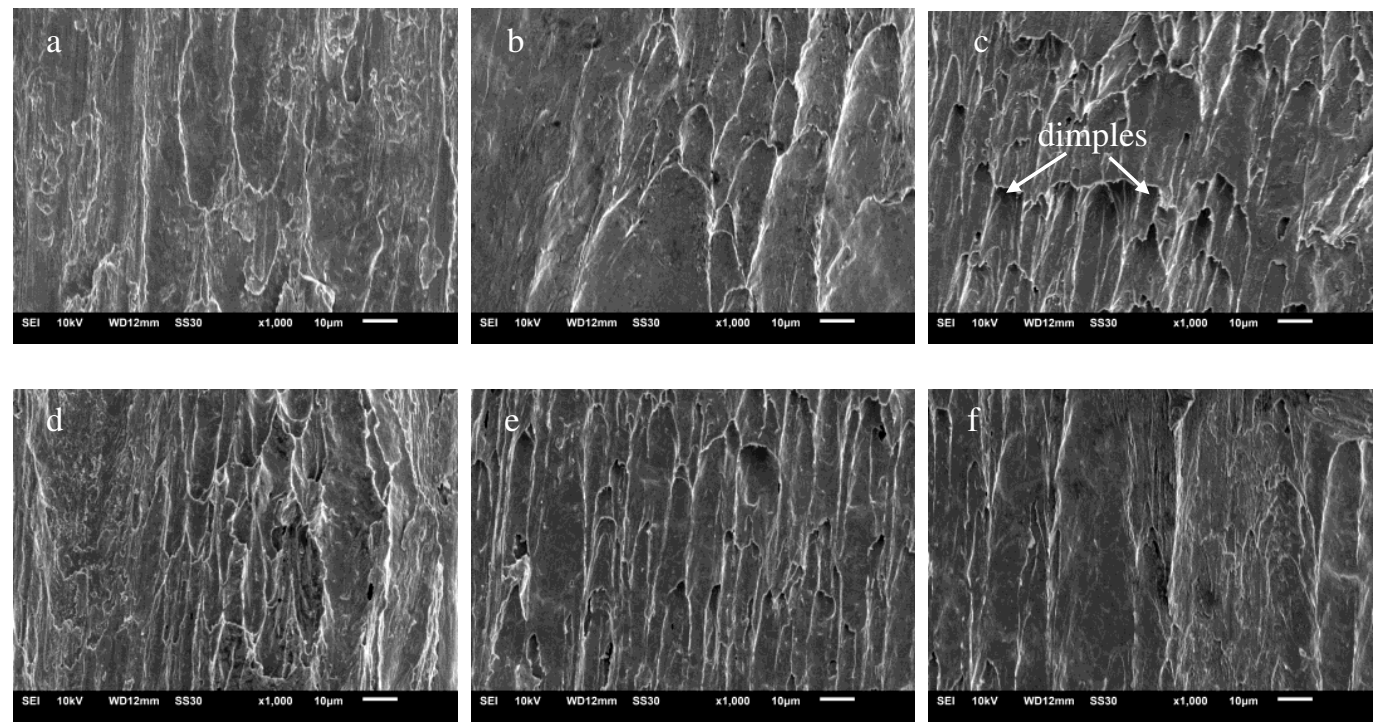

Fig.8 SEM graphs of fracture morphology of $\mathrm{Sn}-x \mathrm{SiC}$ solder under tensile test: (a) $x=0$, (b) $x=0.2$, (c) $x$

$$
=0.4, \text { (d) } x=0.6 \text {, (e) } x=0.8, \text { (f) } x=1.0 .
$$

\section{Conclusions}

In this study, the wettability, shear strength and the growth behavior of IMC of Sn- $x \mathrm{SiC} / \mathrm{Cu}$ solder under solid-liquid diffusion at $250{ }^{\circ} \mathrm{C}$ were systematically investigated. The conclusions can be drawn as 
following:

(1) The minor amount of SiC incorporated to Sn solder is conducive to enhancing the wettability of composite solder and the optimal content is $0.6 \mathrm{wt} \%$.

(2) Adding $0.8 \mathrm{wt} \% \mathrm{SiC}$ into pure $\mathrm{Sn}$ solder can impede the diffusion of $\mathrm{Sn}$ and $\mathrm{Cu}$ atoms, hindering the interfacial $\mathrm{Cu}_{6} \mathrm{Sn}_{5}$ IMC growth significantly.

(3) The SiC doping can effectively strengthen the shear strength of $\mathrm{Sn}-x \mathrm{SiC}$ composite solder, and the fracture mode converts a brittle and ductile mode to a ductile mode after adding SiC into Sn solder.

\section{Acknowledgements}

The present work was under support of the Key project of State Key Laboratory of Advanced Welding and Joining (AWJ-19Z04), National Key Research and Development Project (2019YFF0217400), Central Plains science and technology innovation talent plan (ZYQR20180030).

\section{References}

[1] Tu K N, Liu Y X. Recent advances on kinetic analysis of solder joint reactions in 3D IC packaging technology[J]. Materials Science \& Engineering, 2019, 136:1-12.

[2] Xiong M Y, Zhang L. Interface reaction and intermetallic compound growth behavior of Sn-Ag-Cu lead-free solder joints on different substrates in electronic packaging[J]. Journal of Materials Science, 2019, 54(2): 1741-1768.

[3] Tan A T, Tan A W, Yusof F. Influence of nanoparticle addition on the formation and growth of intermetallic compounds (IMCs) in $\mathrm{Cu} / \mathrm{Sn}-\mathrm{Ag}-\mathrm{Cu} / \mathrm{Cu}$ solder joint during different thermal conditions[J]. Science \& Technology of Advanced Materials, 2015, 16(3):033505.

[4] Li M L, Zhang L, Jiang N, et al. Materials modification of the lead-free solders incorporated with micro/nano-sized particles: A review[J]. Materials \&Design, 2021, 197:109224.

[5] Zhang L, Liu Z Q. Inhibition of intermetallic compounds growth at $\mathrm{Sn}-58 \mathrm{Bi} / \mathrm{Cu}$ interface bearing CuZnAl memory particles $(2-6 \mu \mathrm{m})[\mathrm{J}]$. Journal of Materials Science Materials in Electronics, 2020, 31(3):2466-2480.

[6] Xiong M Y, Zhang L, Sun L, et al. Effect of CuZnAl particles addition on microstructure of $\mathrm{Cu} / \mathrm{Sn} 58 \mathrm{Bi} / \mathrm{Cu}$ TLP bonding solder joints[J]. Vacuum, 2019, 167:301-306.

[7] Zhang L, Long W M, Wang F J. Microstructures, interface reaction, and properties of Sn-Ag-Cu and $\mathrm{Sn}-\mathrm{Ag}-\mathrm{Cu}-0.5 \mathrm{CuZnAl}$ solders on Fe substrate[J]. Journal of Materials Science: Materials in Electronics, 2020, 31(9):6645-6653.

[8] Jiang N, Zhang L, Long W M , et al. Influence of doping Ti particles on intermetallic compounds growth at $\mathrm{Sn} 58 \mathrm{Bi} / \mathrm{Cu}$ interface during solid-liquid diffusion[J]. Journal of Materials Science: Materials in Electronics, 2021, 32:3341-3351.

[9] Chang S Y, Jain C C, Chuang $\mathrm{T} \mathrm{H}$, et al. Effect of addition of $\mathrm{TiO}_{2}$ nanoparticles on the microstructure, microhardness and interfacial reactions of $\mathrm{Sn} 3.5 \mathrm{AgXCu}$ solder[J]. Materials \& Design, 2011, 32(10):4720-4727.

[10] Chellvarajoo S, Abdullah M Z. Microstructure and mechanical properties of $\mathrm{Pb}$-free $\mathrm{Sn}-3.0 \mathrm{Ag}-0.5 \mathrm{Cu}$ solder pastes added with $\mathrm{NiO}$ nanoparticles after reflow soldering process[J]. Materials \& Design, 2016, 90:499-507.

[11] Wang F J, Liu L T, Li D Y, et al. Electromigration behaviors in Sn-58Bi solder joints under different current densities and temperatures[J]. Journal of Materials Science Materials in Electronics, 2018, 29:21157-21169.

[12] Hasnine M, Vahora N, et al. Microstructural and mechanical behavior of SnCu-Ge solder alloy subjected to high temperature storage[J]. Journal of Materials Science. Materials in Electronics, 
2018, 29(11):8904-8913.

[13] Wu J, Xue S B, Wang J W, et al. Effect of Pr addition on properties and Sn whisker growth of Sn-0.3Ag-0.7Cu low-Ag solder for electronic packaging[J]. Journal of Materials Science Materials in Electronics, 2017, 28(14):10230-10244.

[14] Hou Z Z, Zhao X C, Liu Y, et al. Comparative study on the hourglass-like joint of electroplated Sn-base solder reinforced by adding $\mathrm{Ag}_{3} \mathrm{Sn}$ nanoparticles and $\mathrm{Ag}$ micro-alloying elements[J]. Materialia, 2020, 9:100558.

[15] Zhang Y, Lu C J, Liu Y S, et al. The effect of Bi addition on the formation of metal whiskers in $\mathrm{Ti}_{2} \mathrm{SnC} / \mathrm{Sn}-\mathrm{xBi}$ system[J]. Vacuum, 2020, 182:109764.

[16] He H, Huang S Y, Xiao Y, et al. Diffusion reaction-induced microstructure and strength evolution of $\mathrm{Cu}$ joints bonded with Sn-based solder containing Ni-foam[J]. Materials Letters, 2020, 281:128642.

[17] Xu K K, Zhang L, Jiang N . Effect of CNTs on the intermetallic compound growth between Sn solder and $\mathrm{Cu}$ substrate during aging and reflowing[J]. Journal of Materials Science: Materials in Electronics, 2021, 32:2655-2666.

[18] Sun L, Chen M H, Zhang L, et al. Effect of addition of CuZnAl particle on the properties of Sn solder joint[J]. Journal of Materials Processing Technology, 2019, 278:116507.

[19] Zhao M, Zhang L, Sun L, et al. Effects of nanoparticles on properties and interface reaction of Sn solder for microelectronic packaging[J]. International Journal of Modern Physics B, 2020, 34(8): 2050064.

[20] Lee C W , Shin Y S, Yoo S H . Effect of SiC nanoparticles dispersion on the microstructure and mechanical properties of electroplated Sn-Bi solder alloy[J]. Journal of Nano Research, 2010, 11:113-118. 
Figures

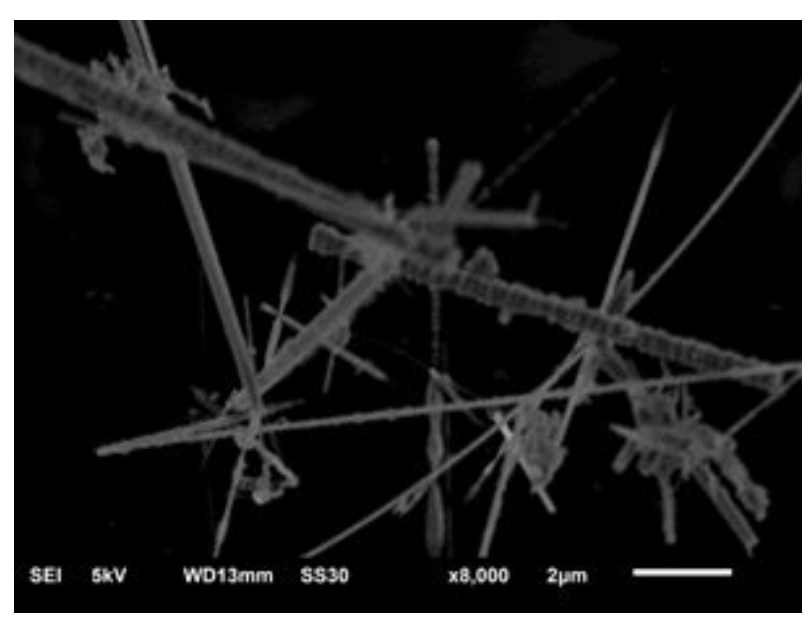

Figure 1

SEM image of SiC.

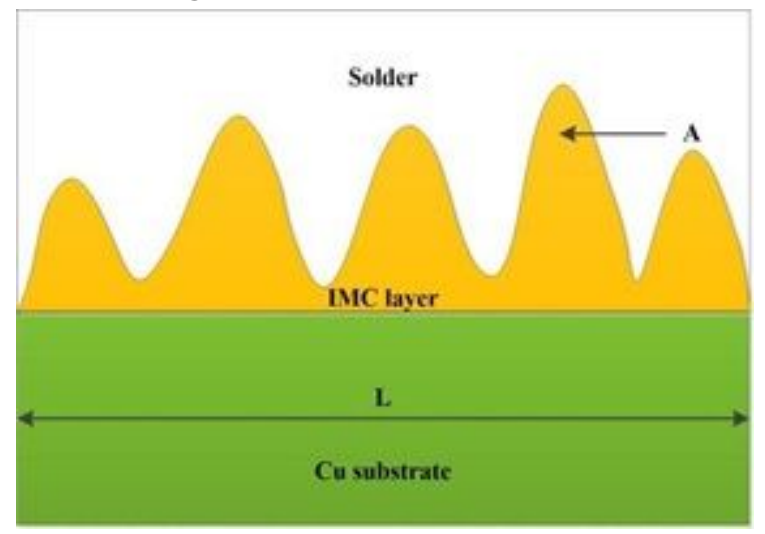

Figure 2

Diagrammatic drawing of interfacial IMC.

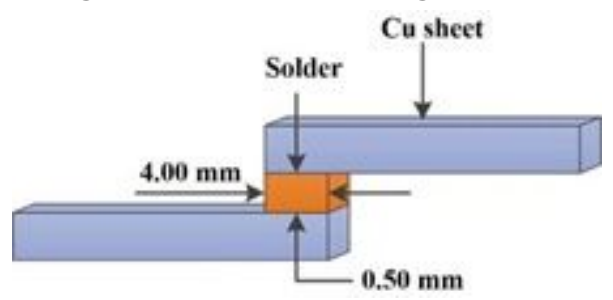

\section{Figure 3}

Diagrammatic drawing of shear test for Sn-xSiC solder. 


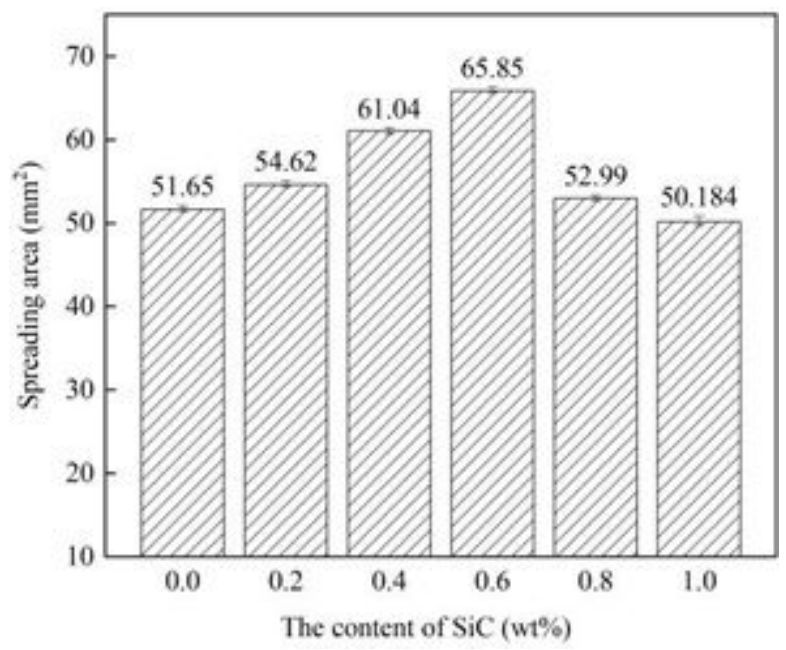

Figure 4

Column diagram of the spreading area varying with the addition content of SiC.
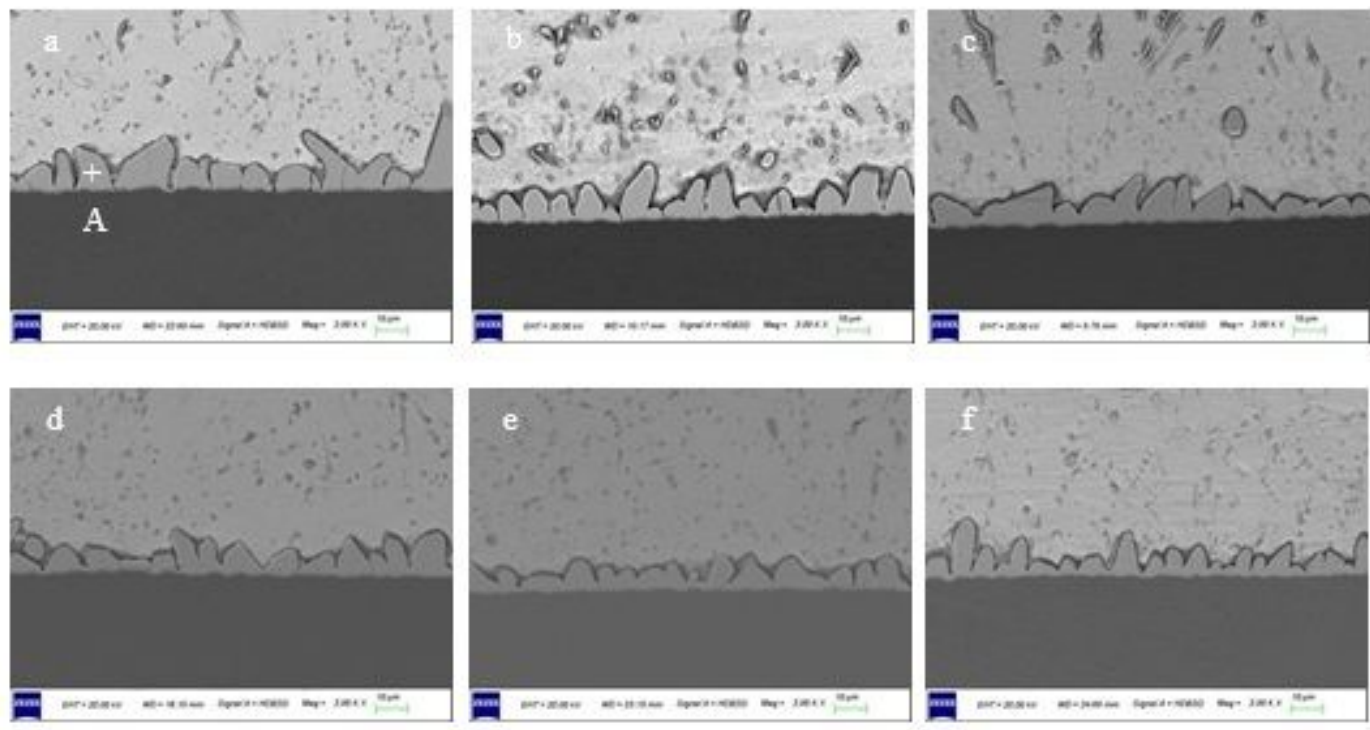

Figure 5

SEM morphology graph of the IMC at Sn-xSiC/Cu solder heated at $250^{\circ} \mathrm{C}$ for $1 \mathrm{~min}:$ (a) $\mathrm{x}=0$, (b) $\mathrm{x}=0.2$, (c) $x=0.4,(d) x=0.6,(e) x=0.8,(f) x=1.0$.

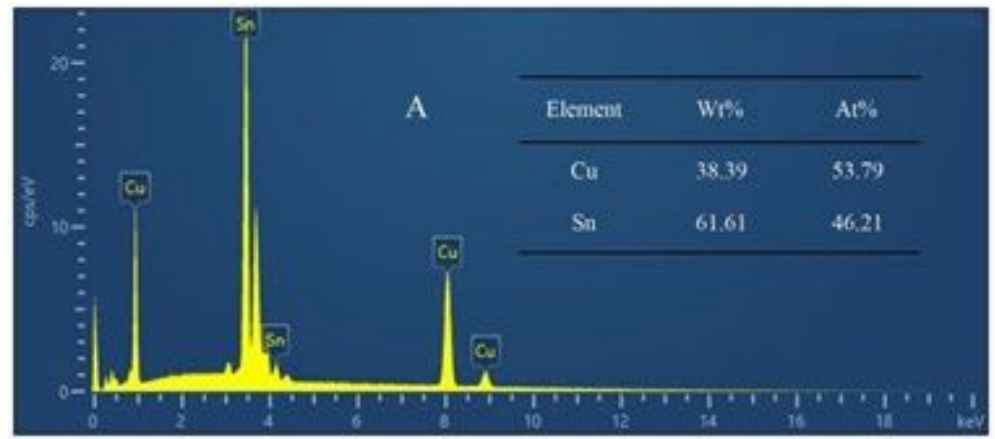

Figure 6 
EDS analysis of IMC layer in Fig.4(a)

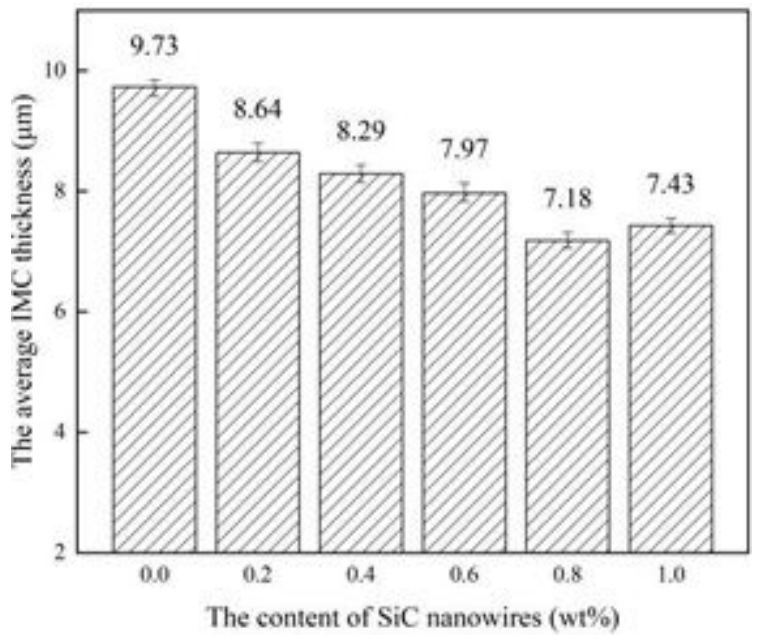

Figure 7

The average IMC thickness as different amount of SiC added to Sn solder.

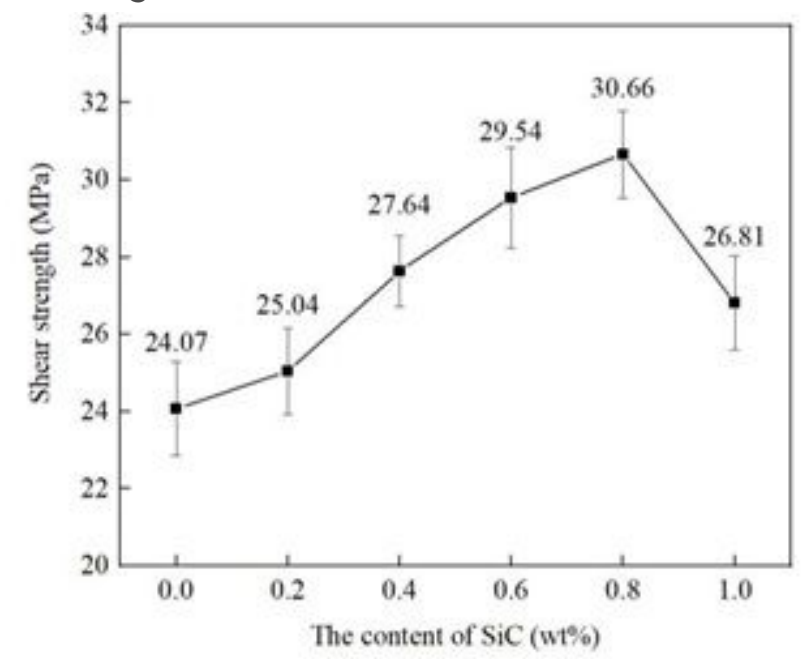

Figure 8

Curve graph of the shear strength as a function of $\mathrm{SiC}$ amount in $\mathrm{Sn}$ solder. 

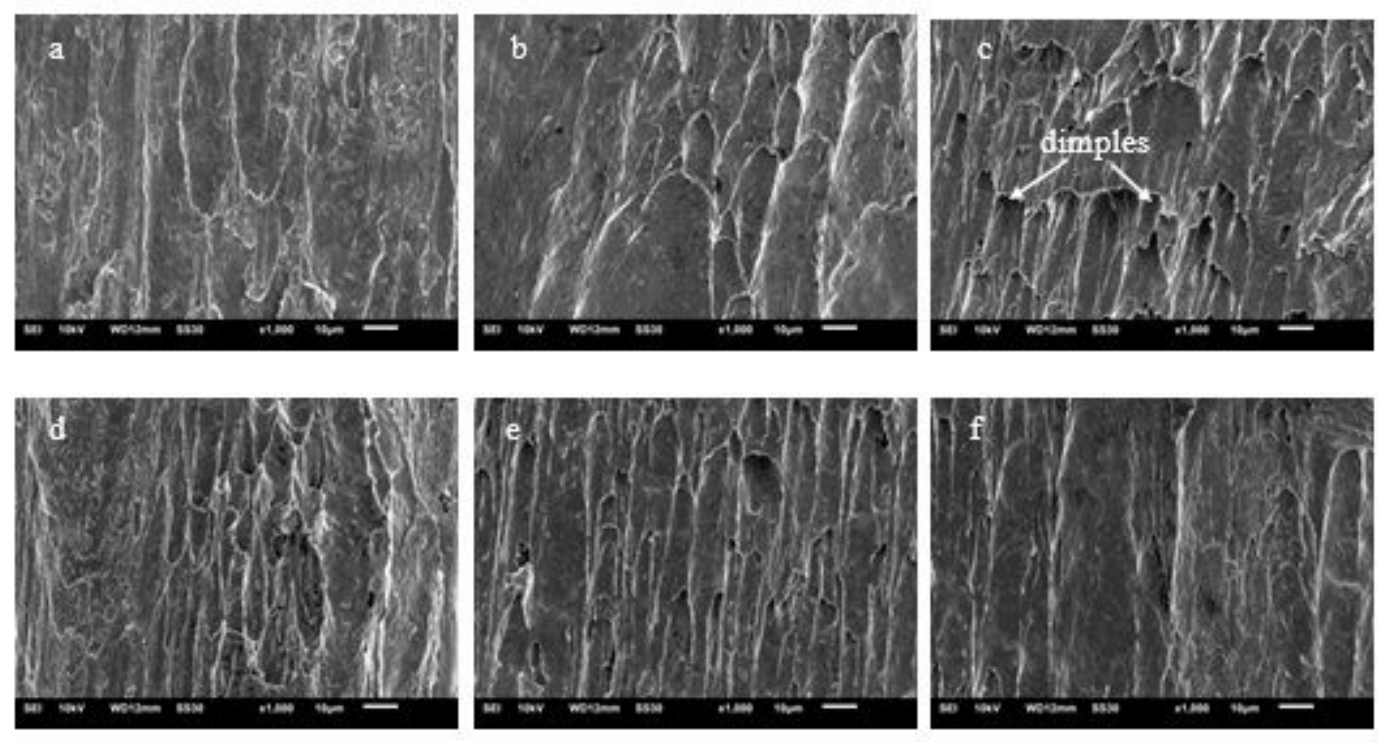

Figure 9

SEM graphs of fracture morphology of Sn-xSiC solder under tensile test: (a) $x=0,(b) x=0.2,(c) x=0.4$, (d) $x=0.6$, (e) $x=0.8$, (f) $x=1.0$. 